\title{
Optimization of Benefit from a Cochlear Implant by a Multi-disciplinary Team
}

\begin{abstract}
Margaret W. Skinner
Abstract : The Clarion, Med-E 1 Combi 40 and Nucleus 22 or 24 Cochlear Implant Systems programmed with the Continuous Interleaved Sampler (CIS), Simultaneous Analog Strategy (SAS), or SPEAK speech coding strategies on the average enable postlinguistically deaf adults to understand $70-80 \%$ of words in open-set sentences by sound alone. Congenitally deaf children who were implanted between 2 and 5 years of age, received intensive spoken language training over a period of years, and use the most recent speech coding strategies, on the average are able to understand $30-40 \%$ of one-syllable, open-set words by sound alone. Several key studies indicate that the earlier a deaf child is implanted, the less language delay there is, the more intelligible their own speech is, and the earlier they are ready to be mainstreamed in normal hearing schools. Adults and children must have appropriately fitted speech processor programs (that are changed as soon as hearing changes) to achieve these levels of success. Because cochlear implants do not provide normal hearing, habilitation for children and rehabilitation for adults are essential. Preoperative evaluation, implantation, and postoperative care can only be effectively provided by close collaboration of a multidisciplinary team.
\end{abstract}

Today, cochlear implants provide more acoustic information to their recipients than was dreamed possible 15 years ago. Since the Nucleus-22 Cochlear Implant System was introduced in 1983, upgrades in speech processors and speech coding strategies have provided remarkable increase in the understanding of speech without reimplantation. Figure 1 shows scores on a one-syllable, open-set word test for nine, postlinguistically deaf adults implanted with the Nucleus-22 device in our program. The group mean scores for the F $0 \mathrm{~F} 1 \mathrm{~F} 2$ speech coding strategy ${ }^{1)}$ was $15 \%$, for the MPEAK strategy $^{1)}$ was $36 \%$, and for the SPEAK strategy ${ }^{2)}$ was $55 \%$. These adults were thrilled with sound from $\mathrm{F} 0 \mathrm{~F} 1 \mathrm{~F} 2$; their understanding more than tripled with SPEAK. Subject 6's scores did not

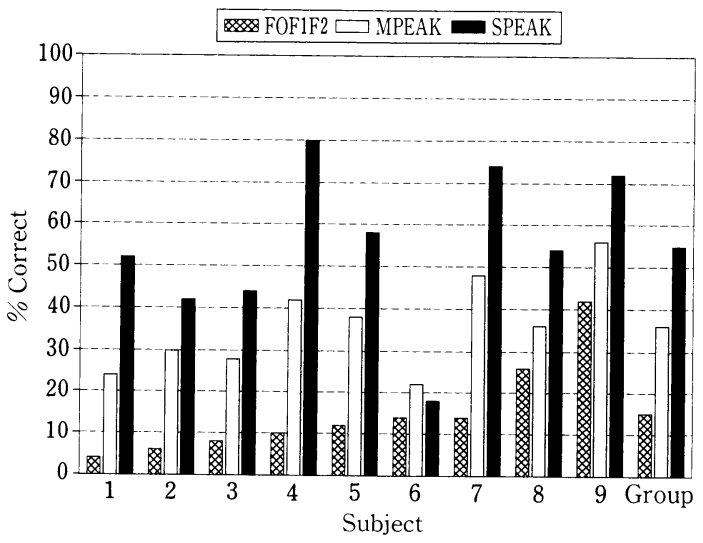

Fig. 1

Department of Otolaryngology-Head \& Neck Surgery Washington University School of Medicine 
Table 1. Group mean and median sentence recognition scores (\% correct) for three cochlear implant systems, speech coding strategy used, number of subjects in each study, sentence test, and test presentation mode(recorded at $70 \mathrm{~dB}$ SPL or live voice).

\begin{tabular}{|c|c|c|c|c|c|c|}
\hline $\begin{array}{l}\text { Cochlear } \\
\text { Implant } \\
\text { System }\end{array}$ & $\begin{array}{l}\text { Speech } \\
\text { Coding } \\
\text { Strategy }\end{array}$ & $\begin{array}{c}\text { \# of } \\
\text { Subjects }\end{array}$ & $\begin{array}{c}\text { Sentence } \\
\text { Test }\end{array}$ & $\begin{array}{c}\text { Presentation } \\
\text { Mode }\end{array}$ & $\begin{array}{l}\text { Mean } \\
\text { Score }\end{array}$ & $\begin{array}{r}\text { Median } \\
\text { Score }\end{array}$ \\
\hline Clarion $^{3)}$ & CIS/SAS & 56 & $\begin{array}{c}\text { CID } \\
\text { (English) }\end{array}$ & recorded & 73 & 86 \\
\hline Med-El Combi 404) & CIS & 50 & $\begin{array}{c}\text { Innbrucker } \\
\text { (German) }\end{array}$ & live voice & 76 & 90 \\
\hline Nucleus $24^{5)}$ & SPEAK & 67 & $\begin{array}{c}\text { CUNY } \\
\text { (English) }\end{array}$ & recorded & 78 & 89 \\
\hline
\end{tabular}

change due to recurrent syphilitic infections and auditory processing difficulty, but she understood sentences better with each new strategy.

The Clarion and Nucleus 22 \& 24 cochlear implant systems are approved by the US Food and Drug Administration (or FDA) for clinical use in adults and children down to 18 months of age. The Med-El Combi $40+$ device has been approved for clinical investigation at participating centers in adults and children. Speech coding strategies available on one or more of these systems include the Continuous Interleaved Sampler (CIS) ${ }^{3)}$ strategy, the Simultaneous Analog Strategy (SAS) and/or the SPEAK $^{21}$ strategy. For each system, 3 month poststimulation sentence test scores are available for sequentially implanted, postlinguistically deaf adults as shown in Table 1. For these tests presented in quiet, scores for all three devices ranged from 0 to $100 \%$ correct. Mean and median scores were almost the same across the three devices ; small differences were probably due to subject sampling and speech test differences. All three devices have the potential to provide similar benefit if prograrmmed appropriately for the individual patient.

Another benefit subjects implanted with these three devices enjoy is the ability to understand speech in noise. For the Nucleus-24 subjects, their post-implantation mean score on the CUNY Sentences presented at a $+10 \mathrm{~dB}$ signal-to-noise ratio in 8 -talker babble was $59 \%$; the median was $67 \%{ }^{6}$. Fifteen years ago, we never expected that cochlear implant recipients would recognize speech in noise this well.

Implant recipients are able to recognize sounds in everyday life that they could not hear with hearing aids prior to implantation. With implants, they can hear and recognize the following sounds : someone calling from the next room; a mother speaking to her child in a normal voice from 2 meters away without speechreading; high-frequency sounds like the doorbell and a microwave oven timer. With hearing aids, they needed the person talking to be no further away than 1 meter speaking at a raised-toloud level, and they needed to watch the talker's face intently for every speechreading cue. The ability of implanted infants and children to hear and attach meaning to spoken words heard during these incidental listening situations without speechreading is critically important for learning language and speech.

To study this ability in adults who used the Nucleus-22 SPEAK strategy, we presented speech tests at 70,60 and $50 \mathrm{~dB}$ SPL, levels which simulate a raised-to-loud, conversational, and soft vocal efforts $^{7)}$. For CUNY Sentences presented in quiet, group mean scores were $89 \%$ at $70 \mathrm{~dB}, 72 \%$ at 60 $\mathrm{dB}$, and $29 \%$ for $50 \mathrm{~dB}$; only two had chance scores at $50 \mathrm{~dB} \mathrm{SPL}^{8)}$. These results clearly support the observations that adults and children with implants understand speech at levels lower than the $70 \mathrm{~dB}$ SPL. They provide the impetus for a national study to determine whether candidacy for implantation should be based on speech recognition ability at $60 \mathrm{~dB}$ instead of $70 \mathrm{~dB}$ SPL. 
The first children implanted with the Nucleus-22 device in 1986 were those who heard little or nothing with hearing aids (PTA $>110 \mathrm{~dB} \mathrm{HL}$ ), were often 5 years of age and older, and had performed less well than those with a little more hearing (PTA from 90-100 dB HL). As implanted children began to perform better than others in their classes, younger children and those with more hearing were implanted $^{9)}$. Pilot studies at centers highly experienced at cochlear implantation and pre-and postoperative management of young children have been conducted with children under 2 years of age. These children are achieving open-set speech recognition as fast or faster than children implanted between 2 and 5 years of age ${ }^{10)}$.

It has been observed that deaf children implanted at greater than 3 years of age develop inappropriate speech production habits based on inadequate auditory information from hearing aids. That is, they lack the normal change in pitch and intensity when speaking a sentence, and they pronounce many vowels and consonants inaccurately. Deaf children implanted by 2 years of age quickly learn appropriate speech production based on auditory information from the implant. Also, their speech is much more natural and intelligible than when children are implanted later.

Several studies support this early implantation in deaf children. Svirsky et $\mathrm{al}^{11}$. have found that at implantation, deaf children's language is substantially delayed compared to normal children. On the average, this delay is maintained but then they start acquiring language at the same rate as normal hearing children. Therefore, the earlier the implantation, the less language will be delayed. For individual children, language development ranges from "approaching normal" to remaining "severely delayed" after implantation.

Ponton et $\mathrm{al}^{12)}$. have found that maturational changes in the human auditory system do not occur without auditory stimulation, and that these changes can be measured directly and objectively with electrophysiological recordings of responses to sound. They have found that the cortical auditory evoked response $\left(\mathrm{P}_{1}\right)$ latencies shorten during maturation in normal hearing infants and children. The
$P_{1}$ latencies of deaf children who are "good implant users" are delayed in time between onset of deafness and implantation compared to normal children, but the normal maturational sequence of latency shortening occurs in these children after implanta. tion.

Yoshinaga-Itano, et al. ${ }^{13)}$ have studied the receptive and expressive language abilities in congenitally deaf and hard-of-hearing children who were identified before and after 6 months of age. About 2 months after identification, they were fit with hearing aids and received ongoing training with their parents. Results show that children identified before 6 months of age had significantly better language development than those identified later. Furthermore, good language development was dependent on very early identification, training, and delivery of an effective auditory signal.

Tyler ${ }^{14)}$ clearly depicts how differently acoustic information is delivered to the auditory nervous system by hearing aids and cochlear implants. For a hearing aid, incoming sound is filtered into bandwidths to apply different amounts of gain, the amplified signal is summed across filters, delivered to the outer ear canal via a receiver, and causes movement of the eardrum, middle-ear ossicles, fluids and sensory hair cells in the inner ear. Only information analyzed with the few remaining hair cells is transmitted to the auditory neurons. For a cochlear implant, incoming sound is filtered into bandwidths, the digitized signal in each bandwidth is processed in real-time, encoded, causes stimulation of individual electrodes implanted in the inner ear, and action potentials in nearby auditory neurons. For each electrode, amplitude of electrical stimulation is programmed to vary between an individual's threshold and maximum acceptable loudness. Because of the tonotopic arrangement of auditory neurons, stimulation of basal to apical electrodes causes high to low-pitched sound percepts. For this reason, the implant can deliver to the deaf ear much more acoustic information at lower sound levels than appropriately fitted hearing aids.

Figure 2 shows an example of the improvement in warble tone thresholds of a group of 26 implanted children ${ }^{15)}$. Mean preimplantation thresholds 


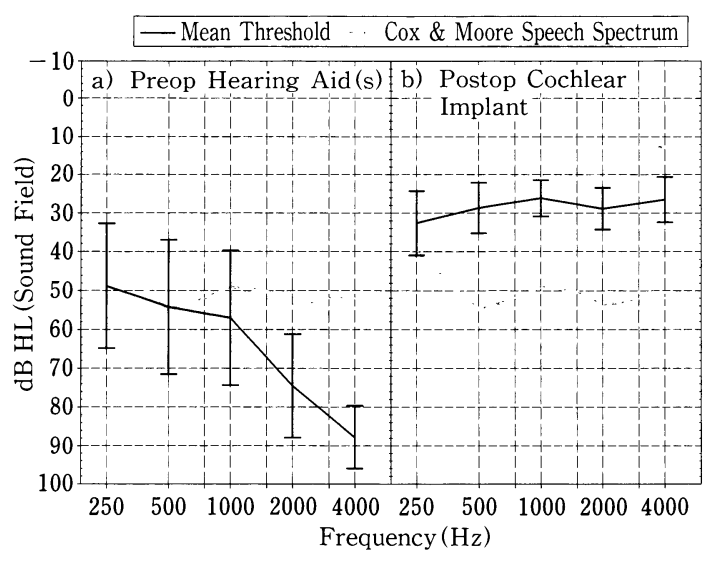

Fig. 2

with hearing aids are shown in relation to the Cox and Moore speech spectrum ${ }^{16}$. With hearing aids, this spectrum was at the mean $500-\mathrm{Hz}$ threshold and at more sensitive levels than mean threshold at all other frequencies. Mean postimplantation thresholds with cochlear implants were much more sensitive than the speech spectrum at all frequencies, and high-frequency sounds through $4000 \mathrm{~Hz}$ were delivered just as well as low-frequency sounds. This improvement in sound-field thresholds only conveys information about how softly these sounds can be heard. Of equal importance, is how well suprathreshold, acoustic information in speech is transmitted to the auditory system.

Preliminary results on implanted children's openset speech recognition by sound alone have been obtained by Geers, et $\mathrm{al}^{17}$. who are studying the effects of various education and rehabilitation models on implanted children's ability to understand, produce and read English. Data are available for 92 children, half the number to complete the study. These children were implanted between the ages of 2-4 years with the Nucleus-22 device; 82 used the SPEAK strategy, and 10 used the MPEAK strategy; evaluation was at 8 to 9 years of age ; and duration of implant use was 4-7 years. They were educated in both oral and/or total communication schools in the United States and Canada. The mean score on recorded BKB Sentences presented at $70 \mathrm{~dB}$ SPL in quiet was $46 \%$; the median was $47.5 \%$. Seventy-four of the 92 children had above $0 \%$ scores ; the range was from 0 to $100 \%$ cor- rect. The mean and median score on the recorded Lexical Neighborhood Test of one-syllable words presented at $70 \mathrm{~dB}$ SPL was $38 \%$. Seventy-nine out of 92 children had scores above $0 \%$; the range was from 0 to $82 \%$.

What does this extraordinary ability of implanted children to understand speech by sound alone mean in everyday life? Vicki Kozak, school principal at Central Institute for the Deaf, said that implanted children still need to exert effort to hear and talk. Compared to their classmates with hearing aids, they need to exert so much less effort. They do not need to speechread constantly to understand what is being said ; they can recognize proper nouns from sound alone; they have fewer breakdowns in communication when they do not understand what is being said ; and they can interact in a much more natural, fluent way. Furthermore, she finds that implant children can converse with her fluently in the highly reverberant school cafeteria, whereas, children with hearing aids struggle to do this.

FDA approval of clinical investigation for implantation of the Clarion device in children occurred just 3.5 years ago (March 1995) ; consequently, less information is available about their performance. Nevertheless, their scores on open-set GASP words and sentences and PBK one-syllable words using the CIS strategy after 3 and 6 months of implant use ${ }^{18)}$ suggest that average speech recognition scores with the Clarion and Nucleus devices will be very similar for the same duration of use.

In June 1998, Boothroyd-Turner and Boothroyd reported results of a two year study of speech perception, language and literacy acquisition of eight deaf children from the Toronto, Canada School System ${ }^{19)}$. Initially, the children spent half day with a skilled teacher of the deaf and the other half mainstreamed in neighborhood schools. By the end of the study, three were fully mainstreamed. The average age at identification of hearing impairment was 16 months; average pure-tone thresholds were $107 \mathrm{~dB} \mathrm{HL}$; average age at implantation was 5 years; and mean duration of implant use was 4.5 years at the end of the study. All were implanted with the Nucleus-22 and used the SPEAK strategy. Their mean score on CVC one-syllable words was 
$34 \%$, on hard sentences was $62 \%$, and on easy sentences was $85 \%$. These scores represent a remarkable amount of open-set speech recognition. Their discrimination of speech feature contrasts was evaluated with the closed-set, IMSPAC test ${ }^{20)}$. The group mean, composite score of $77 \%$ (corrected for chance) on the audio-only portion of the IMSPAC test for these 8 implanted children was compared with similar data for 89 children with hearing losses between 70 and $120 \mathrm{~dB}$ SPL who used hearing aids. The implanted children's performance was similar to that of children with severe hearing losses between 70 and $80 \mathrm{~dB}$ HL who used hearing aids.

For children and adults to have access to auditory information that cochlear implants can provide, the implant speech processor must be programmed so that incoming sound is matched to the electrical hearing of the individual. As described above, it is clear that the most recent speech coding strategies should be chosen for use. That is, Nucleus-22 recipients should be upgraded to the Spectra 22 processor and SPEAK strategy, and Clarion recipients should be upgraded to the "S" series processor. New patients should be implanted with the Clarion, Nucleus 24 or Med-E 1 Combi $40+$ implants. Once a speech coding strategy and appropriate rate of electrode stimulation have been chosen, then the range between hearing threshold and maximum acceptable loudness level on each electrode needs to be determined. For older children and adults, these results are readily obtainable. For infants and young children, thresholds need to be estimated by clinicians skilled at obtaining behavioral responses, acoustic reflex thresholds and electrical auditory brainstem responses. Initial minimum and maximum stimulation levels on each electrode in the speech processor prograrn or MAP are selected. For older children and adults, these minimum and maximum levels are based on thresholds and maximum acceptable loudness levels adjusted so that loudness is balanced across thresholds at both levels. For infants and children, minimum levels are set at the estimated thresholds and maximum levels are set higher (e.g., 15 levels). With these levels and choices of other parameters, a program is created so that incoming sound is processed and delivered to the individual. Adjustments are made in the minimum and maximum stimulation levels to make loud sounds not too loud or distorted, soft sounds audible, and normal speech levels comfortably loud when the processor sensitivity and/or volume control are set at a mid-range setting. Further adjustments are made after use in everyday life so that the normal range of sound levels encountered are comfortably loud, and speech is as clear as possible. This process of adjustments occurs over a sequence of sessions, particularly with young children.

Sun et $\mathrm{al}^{21)}$. have compared two adults' thresholds and maximum acceptable loudness levels with the MAP minimum and maximum levels found to be most useful in everyday life (see their Figure 1 ). The MAP minimum and maximum level contours for Subject 6 were the same as the threshold and maximum acceptable loudness contours across all the electrodes. For Subject 1 , the MAP minimum level contour was a little higher than the thresholds, and the MAP maximum level contour was much lower than the maximum acceptable loudness levels on each electrode. It is common for there to be differences between behavioral measurements on each electrode and the optimized values for the MAP minimum and maximum stimulation levels.

Electrical hearing can fluctuate or change just as acoustic hearing does ${ }^{22,23)}$. There are hearing changes from initial stimulation with the implant to first stabilization; after stabilization there can be fluctuations associated with infections or health status (e.g., sinus or middle-ear infections), and changes associated with the underlying disease process (e.g., otosclerosis). An example of hearing changes from initial stimulation to first stabilization is shown in Figure 3. Common Ground stimulation was used on all electrodes until 4 weeks post-stimulation when bipolar modes were used on electrodes 7-11 to avoid facial nerve stimulation by spacing the active and return electrodes further apart to decrease the current needed. There was an increase in minimum and maximum levels that continued to occur across electrodes until 9 weeks later. Although this amount of change is unusual, it clearly shows how important it is to continue repro- 


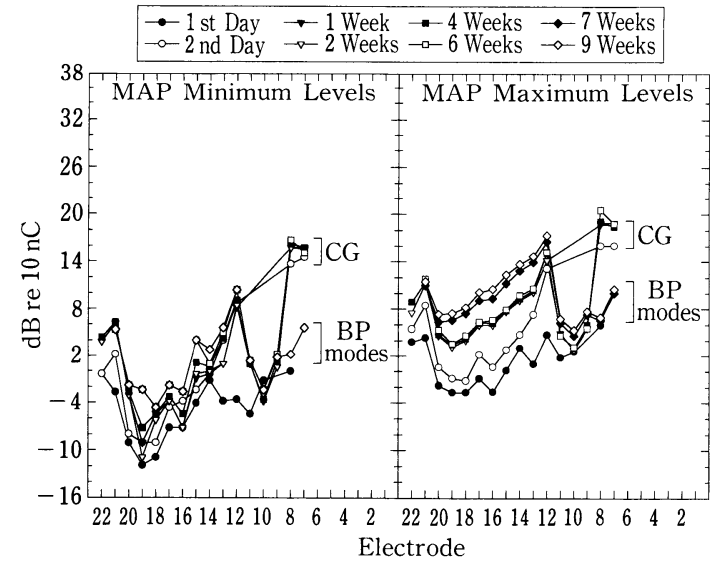

Fig. 3

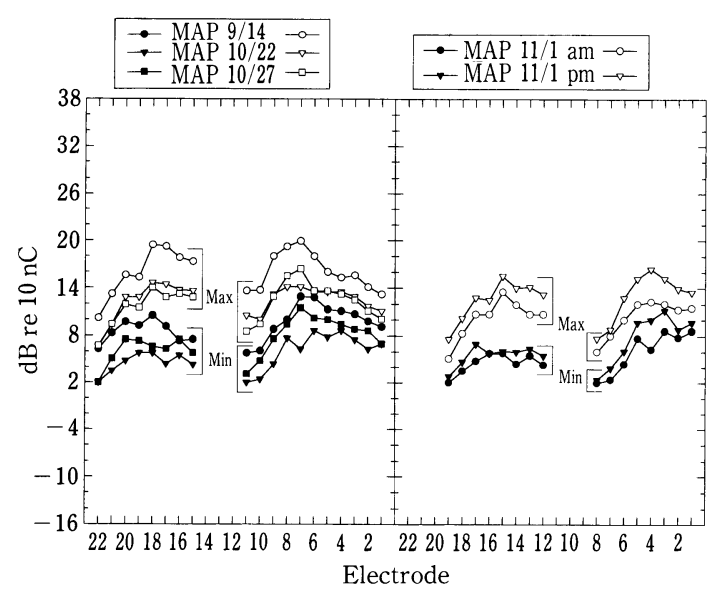

Fig. 4

gramming until stabilization occurs. Figure 4 shows fluctuations for a child who had persistent middle ear problems. Five sets of MAP maximum and minimum levels over 6 weeks are shown. A large decrease in minimum and maximum levels occurred from September 14 to October 22 ; whereas, on October 27, minimum levels increased. On November 1 in the morning, her maximum and minimum levels were more sensitive when she came to the school audiologist complaining that sound was too loud ; after lunch, she complained sound was too soft, and her maximum and minimum levels had risen ${ }^{24)}$. This amount of fluctuation is unusual but does occur.

In adults and children served in the New York University and Washington University Cochlear
Implant Programs as well as at CID and St. Joseph Institute for the Deaf, approximately $25 \%$ have relatively frequent fluctuations in hearing after initial stabilization. Over $75 \%$ require changes in minimum and maximum stimulation levels in MAPs at regular intervals ${ }^{25}$. For children, signs of fluctuations in electrical hearing may be a decrease in responsiveness to sound, decrease in the clarity of their speech, or sound is too loud at the usual sensitivity and/or volume control setting. To provide maximum access to sound, it is essential to evaluate a child's electrical hearing as soon as possible and modify the MAP appropriately. A day without an appropriate MAP is a day lost to learning.

Habilitation for children and rehabilitation for adults are essential because a cochlear implant never provides normal hearing. Deaf children always will need intense training and parental support to learn spoken language and communication skills. Without this training and support, implanted children become non-users of their devices. Many professionals assume that adults with acquired deafness get so much benefit from their implants that they do not need rehabilitation. However, adults need guided practice with a skilled clinician to learn effective ways to repair breakdowns in accurate communication (particularly on the telephone), what telephones/connectors provide best speech reception, and ways to develop good visual attention and integration of auditory-visual cues.

The following is an example of the US FDA approved audiological guidelines for selecting patients for implantation for the Nucleus-24 device. Postlinguistically deaf adults must have bilateral, sensorineural hearing impairment and obtain limited benefit from appropriately fitted binaural hearing aids. "Limited benefit" is defined as test scores of $<40 \%$ correct in the best-aided listening condition on tape-recorded tests of open-set sentence recognition. Prelinguistically or perilinguistically deaf adult candidates must have profound, bilateral, sensorineural deafness and not benefit from appropriate amplification. Of great importance is the fact that the criterion is based on aided speech recognition and not pure tone thresholds. The guidelines for children from 18 months through 17 years are as 
follows. They should have bilateral profound sensorneural deafness and demonstrate little or no benefit from appropriate binaural hearing aids." Little or no benefit" is defined in younger children as those who show lack of progress in development of simple auditory skills with appropriate amplification and participation in intensive aural habilitation over a 3-6 month period. The MAIS ${ }^{26)}$ or ESP $^{27)}$ are used for evaluation of these skills. In older children, there must be a 3 to 6 month hearing aid trial if the child has had no previous experience. They are implant candidates if aided scores on the open-set, Lexical Neighborhood Test $\left(\right.$ LNT) ${ }^{28)}$ are less than $20 \%$.

The patient must be the focus of coordinated care. The goal must be for each patient to have the best opportunity to fulfill his or her capability to use the cochlear implant effectively. Achievement of this goal is critically dependent on how effectively a multi-disciplinary team provides the essential services. Each team member brings his or her own expertise to the process. This process includes preoperative evaluation to determine candidacy, decision to implant, implantation, follow-up medical care, well-coordinated post-implantation programming of the speech processor, rehabilitation for adults and habilitation/education for children. The multicisciplinary team members for adult programs include the surgeon, audiologist and/or speech pathologist (who conduct the pre-and post-operative evaluation, speech processor fitting, and rehabilitation training), the patient and family member or friend, and affiliated members such as the psychologist and radiologist. Added team members for children's programs include a teacher of the deaf (and school staff), special speech/hearing/language therapists, and the parents and child. Communication and effective collaboration among team members is essential to optimize patient benefit from the implant. Team members are richly rewarded by sharing in the transformation caused by a cochlear implant in each patient's life.

\section{References}

1) Skinner, M.W.,Holden,L.K.,Holden,T.A,et al. : Performance of postlinguistically deaf adults with the Wearable Speech Processor (WSP) and Mini Speech Processor (MSP) of the Nucleus Multi-Electrode Cochlear Implant. Ear and Hearing, $12: 3-22,1991$.

2) Skinner, M.W., Clark, G.M., Whitford,L.,et al. : Evaluation of a new spectral peak (SPEAK) coding strategy for the Nucleus 22 Channel Cochlear Implant System. American Journal of Otology, 15(Suppl 2) : 15-27, 1994.

3) Wilson, B.S., Lawson,D.T., Finley, C.C. et al. : Design and evaluation of a continuous interleaved sampling (CIS) processing strategy for multichannel cochlear implants. Journal of Rehabilitation Research and Development, 30 (1) : 110-116, 1994.

4) Kessler, D. R. (1998), : Personal communication on CLARION CIS/SAS preference study.

5) Helms, J., Muller, J.. Schon, F., et al. (1997) . : Evaluation of performance with the COMBI 40 Cochlear Implant in adults ; A multicentric clinical study, ORL 59 : 23-35.

6) Cochlear Corporation (1998). The Nucleus 24 Cochlear Implant System. US FDA Premarket Approval Application (PMA \# P 9700519), approval date: June 25, 1998.

7) Pearsons, K. S., Bennett, R. L., Fidell, S. (1976) . : Speech levels in various environments. Canoga Park, California : Bolt Beranek and Newman Report No. 321.

8) Skinner, M. W, Holden, L. K., Holden, T. A., et al. : Speech recognition at simulated soft, conversational and raised-to-loud vocal efforts by adults with cochlear implants. Journal of the Acoustical Society of America, $101: 3766-3782$, 1997.

9) Waltzman, S. B., Cohen, N. L., Gomolin, R. H., et al. : Long-term results of early cochlear implantation in congenitally and prelingually deafened children. American Journal of Otology, 15(Suppl 2) : 9-13, 1994.

10) Waltzman, S.B., Cohen, N.L. : Cochlear implantation in children younger than 2 years old. American Journal of Otology, 19 : 158-162, 1998.

11) Svirsky, M. A., Robbins, A. M., Miyamoto, R. $\mathrm{T}$. : Language development and its relation to 
speech perception in prelingually deaf children with cochlear implants, presented at the 1997 Conference on Implantable Auditory Prostheses, Pacific Grove, California, August 17, 1997.

12) Ponton, C. W., Don, M., Eggermont, J. J., et al. : Auditory system plasticity in children after long periods of complete deafness. NeuroReport, $8: 61-65,1996$.

13) Yoshinaga-Itano, C., Sedey, A. L., Coulter, D. K., et al. : Language of early-and lateridentified children with hearing loss. Pediatrics, 102 : 1161-1171, 1998.

14) Tyler, R. S. : What can we learn about hearing aids from cochlear implants? Ear and Hearing, 12(6) Suppl : 177 S-186 S, 1991.

15) Stroer, B. S. : Personal communication about sound field thresholds pre-and postimplantation for children who attend St. Joseph Institute for the Deaf, St. Louis, Missouri, 1998.

16) Cox, R. M., Moore, J. N. : Composite speech spectrum for hearing aid gain prescriptions. Journal of Speech and Hearing Research, 31 : 102-107, 1988.

17) Geers, A., Davidson, L. S., Brenner, C. et al. (1998). : Personal communication on research funded by National Institute on Deafness and Other Communication Disorders grant \# DC 03100 .

18) Osberger, M. J., Fisher, L. J., Murad, C. : Clinical results with the CLARION multi-strategy cochlear implant in children. In Clark GM (ed), Cochlear Implants. Bologna, Italy : Monduzi Editore, 291-295 pp., 1997.

19) Boothroyd-Turner, D., Boothroyd, A. : Characteristics and attainment of congenitally deaf children with cochlear implants, presented to the Alexander Graham Bell Association for the Deaf Convention, Little Rock Arkansas, June 30, 1998.

20) Boothroyd, A. : Speech perception measures and their role in the evaluation of hearing aid performance in a pediatric population. In Feigin JA \& Stelmachowicz PG (eds), Pediatric amplification. Omaha, NE : Boys Town National Research Hospital, 77-91 pp., 1991.

21) Sun, J. C., Skirmer, M. W., Liu, W. Y., et al. : Optimization of speech processor fitting strategies for Chinese-speaking implantees. Laryngoscope, $108:$ :560-568, 1998.

22) Shapiro, W. S., Waltzman, S. M. : Changes in electrical thresholds over time in young children implanted with the Nucleus cochlear prosthesis. Annals of Otology, Rhinology \& Laryngology, 104 (Suppl 166) : 177-178, 1998.

23) Skinner, M.W., Binzer, S.B., Holden, L.K., et al.: Hearing changes in adults with cochlear implants. Seminars in Hearing, 16 (3) : 228-239, 1995.

24) Davidson, L. S. (1997) . : Personal communication about child at Central Institute for the Deaf.

25) Skinner,M.W., Holden,L.K., Holden, T.A., et al. : Threshold and maximum acceptable loudness level variability : implications for selection of minimum and maximum stimulation levels for implant use, presented at the 1997 Conference on Implantable Auditory Prostheses, Pacific Grove, California. August 20, 1997.

26) Robbins, A. M., Renshaw, J. J., Berry, S. W. : Evaluating meaningful auditory integration in profoundly hearing impaired children. American Journal of Otology 12(Suppl) : 144-150, 1991. 